\title{
Constructing Portfolios Together: Promoting Student/Faculty Metacognition
}

\author{
Sonya Corbin Dwyer \\ and \\ donna patterson \\ University of Regina
}

\begin{abstract}
This article is intended both to share the authors' experiences using portfolios as a teaching and evaluative tool in post-secondary undergraduate educational psychology courses, and to act as a means of reflecting on their own teaching. Their work arises out of a desire to find better ways of assessing both their students, and their own performance, as well as to deal conceptually with assessment. What they recount here are their struggles and successes in modeling an alternative assessment technique with their students, while also using the same technique as a tool for self-examination of their own practice. Much of the article is presented in a unique voice/countervoice format.
\end{abstract}

\section{Introduction}

The portfolio concept is not new. Artists, photographers, architects, and financial advisors have long used this approach. Discussions about and expectations in "portfolio assessment" at the university level have mushroomed in the last few years. This approach to assessment has been used to evaluate everything from literacy (Irwin DeVitis, 1996; Scanlan and Heiden, 1996; Rogers and Tucker, 1993), to social studies (Hootstein, 1998; Ross, 1996), to mathematics (Liebars, 1999; Zollman and Jones, 1994), to teaching (Curry and Cruz, 2000; Lyons, 1999; Boileau, 1993). Portfolios have also been used to assess post-secondary programs servicing individuals with disabilities (Bagget, 1994; Valeri-Gold, 1992). There is suggestion that portfolios may be particularly applicable to the assessment of preservice teachers (Rakow, 1999; Morgan, 1999; Ryan and Kuhs, 1993; Stowell, 1993; Zelazek, 1993).

Constructivist theories claim that knowledge is actively constructed by learners as they make meaning. In this light, the portfolio becomes an external artifact in which preservice teachers are actively engaged in creating new ideas

Sonya Corbin Dwyer, Ph.D., teaches Educational Psychology at the Faculty of Education, University of Regina. donna patterson, Ph.D., is Coordinator of Special Education at the Faculty of Education, University of Regina. 
and meanings. They can reflect upon this artifact and share it and their reflections with others. Portfolios therefore involve two intertwined types of construction: the construction of knowledge in the context of constructing a personally meaningful artifact (Kafai and Resnick, 1996). Also, instructors can reflect on their teaching methods by sharing their portfolios with peers and students.

Drawing on Lyons (1999), portfolios function in three important ways: helping teachers define good practice, stimulating reflection on their own teaching and learning, and both acknowledging and refining practices in which teachers regularly ask their students to engage. Whether or not one agrees with Lyon, portfolios offer particular opportunities for preservice teachers and their instructors to construct meaning about teaching and learning as well as to reflect on learning to teach (an example of such an opportunity is using portfolios to connect field experience, course content, and pedagogical beliefs).

Currently, portfolios are part of the changing face of assessing student progress and, more and more faculties of education are using them as tools for assessing the progress of teachers-in- training. Often, preservice teachers have a grasp of the necessity of such techniques, are able to explain their application in the tests that they write and, less frequently, are asked to demonstrate that understanding. We however contend that this is not enough. Faculty could use portfolios to examine their own practice, and in that way, model and perhaps address Lyons' concern: that what students and instructors learn about and do with portfolios in the faculty stays in the faculty and in the class. Our exploration is an attempt to model teaching behaviour i.e. not to teach a procedure for action but to model it within teaching

In our classes, we have used portfolios to build bridges between content areas in educational psychology. By looking for connections and patterns, we (students and instructors) become more integrative in our teaching and learning. We decided to include portfolio assessment in our second and third year courses to determine the differences we noted in authenticity, degree of self-directedness and commitment on the part of students, as well as to examine the responsiveness of our own practice and our changing understanding of the functions of portfolios. We "decided...to listen very carefully to [students] and to let their voices and their longings find a place” (Kozol, 1991, p. 7). One basic goal guided our actions: getting our students to transfer what they had learned in our courses to the reality of the classroom.

As indicated earlier, portfolios are intended to provide students with meaningful contexts as well as connections to 'real-life' situations in which the course content is useful (Woolfolk, 1999). Portfolios are therefore used as one way to invite and challenge students to transform and reorganize their existing cognitive structures in order to become active and reflective learners. If portfolios are described as collections of student work meant to demonstrate progress, the critical word is indeed 'demonstrate.'

When progress can be determined by work over time through personal reflections, records of accomplishments, notations on skill development or construction of projects, the teacher has solid evidence of student achievement. Portfolios house such collections, providing a 'movie' of student work rather 
than a snapshot. It seems to make sense that those individuals who will be assessing children in our schools should be assessed in a like manner as is now used in schools. Besides, do we not want to have a thorough grasp of what any particular future teacher is capable of doing and learning? How else would we know of creative spurts, of commitment, of genuine learning?

As instructors, constructing our own portfolios provided us with meaningful contexts in which to reflect upon, and share our teaching methods. It also allowed us to get to know each other as well as our students in ways that go beyond paper and pencil and speak more directly to practice.

Our intention is this paper is to share portfolios constructed by our students and by us. Such portfolios demonstrate growth, strengths, and limitations in achieving the course objectives and in setting personal and professional goals. One course had the students and instructor construct portfolio as they responded to classroom assessment situations. In the other course, the instructor and students used portfolios to demonstrate their understanding of children. Both types of portfolios resulted in products which further inform the learning process.

We both share the philosophy that students, regardless of professional developmental level, need to be assessed on their ability to use the knowledge, skills, processes, and attitudes that have been facilitated throughout their time in our courses. We also know that the approach to assessment we had chosenportfolios, reflected our assumptions about the nature of learning and the role of the participants in their learning. We wanted to include students in conversation, to better examine what they were learning, how they believed they learned as well as to get a sense of what assisted or prevented them in coming to know.

For our students, it meant involving them in the assessment process although they were rather hesitant. Would this mean more work for them? Why couldn't they just do a couple of term papers, like they had done for that other 'prof". Was this going to be fair? Good questions. Students in schools would likely have asked the same or similar ones.

Student and instructor portfolios are examined in light of the following questions: What do they say about learning? What do they say about declarative knowledge? What do they say about tacit knowledge? What do they say about metacognitive understandings? What do they tell us about teaching practices? How can they inform teaching practices? In what ways do they convey students' needs? Finally, our use of portfolios for peer evaluation, provides both preservice and university teachers with a model that they may use in their own professional development.

\section{Student Portfolios}

It is not enough to preach about alternative assessment. If preservice teachers are expected to adopt multiple assessment methods, then they must experience them. (Liebars, 1999, p. 164).

Portfolio assessment, when planned and implemented thoughtfully... helps students and teachers re-examine their work. (Fensick and Parsons, 1999, p. 92). 
Taking the quotes above as a starting point, the format of the following discussion of our student portfolios, examines the context of our classes, the task we set out for our students and ourselves, our evaluation of the resulting portfolios, the themes we saw, and our reflections of what occurred. We each speak in turn and close each section by speaking together.

\section{The Context}

donna: I knew that I would be teaching a class on student development in the fall. Often such classes are not grounded in experience but rather become classes in which information about children is transmitted. Children become objects of study. While I had used portfolio assessment before, I had never used it in a preservice class that focused on learning about elementary students. I chose to use this method of assessment because I wanted to push my students to actively seek experiences which would extend and deepen their understandings of children and youth. Such experiences allowed for the presence of children as subjects thus enhancing the possibility of learning about through interaction with.

Sonya: I teach a course on classroom assessment and evaluation. This course focuses on authentic forms of assessment within a constructivist orientation. Integrated with other evaluation techniques modeled in this course, I use portfolios to provide an opportunity for students to develop and assess their own learning.

Together: We both work in a preservice education program in which the melding of theory and practice is fundamental. Issues around practicing what we preach are particularly sensitive ones. It is in response to this context as well as a desire to model best practice that led us to initially take on the whole idea of portfolio as an opportunity to challenge our students, to challenge ourselves, to focus on experience and learning from experience.

\section{The Task}

donna: The task was to demonstrate active learning about personal/professional development that focused on an understanding of elementary student development. Students in the class were asked to provide evidence from three to five experiential activities illustrating their efforts to understand children.

Sonya: Students were provided with a menu that included mini case-studies, reflective prompts, observational tasks, and invited assessment activities. For the final portfolio submission, students selected ten items to document their growth. These items were accompanied by a guide which highlighted four areas: their most important learning experiences, personal reactions to the portfolio, results of their peer assessment, and goals and implications for their professional practice.

Together: In both portfolios, students were invited to include relevant work from other courses as well as school and community resources. 


\section{Evaluating the Portfolios}

donna: My first step was to develop a general scoring rubric. I used my course objectives to set up five overriding criteria. The focus of the course was student development so one of the criteria was to demonstrate an understanding of elementary school children. This criteria became more critical in my thinking as time passed. Having worked with teachers who claimed to know all about child development but had problems seeing how development affects students behaviour or learning, another criteria had to do with application/transference or making connections between theory and practice as teachers. I wanted a high degree of self-reflection (Macrorie, 1984). I believe that examining one's own learning is a powerful tool for deepening and expanding learning. As well, I wanted to include participation, risk, and initiative, knowing that these are important both in learning and in demonstrating what has been learned. I wanted to be able to understand what was presented so, clarity became the fifth criteria.

My next step was to develop a portfolio analysis guide in which I described what the portfolio might look like at various stages. I also wrote a cover letter reminding the students that they already had some first hand experience with portfolios. I gave these to students in the first class. I also showed them several sample portfolios that were done by students in other courses.

Sonya: I also developed a general scoring rubric. My rubric included three criteria: application of knowledge, synthesis of knowledge, and critical thinking. One of my main objectives was to make connections between knowledge and practice. Students were encouraged to construct and test their own links. This fostering of connections was particularly pertinent when it came to the three oneweek blocks the students spent in schools while taking the course. These oneweek blocks became opportunities for the students to make meaning in 'real' classroom settings.

Together: The two rubrics, developed independently, had two interesting overlaps: a focus on transference and application, and a demand for clarity.

\section{Themes}

donna: As some readers will no doubt suspect, at the end of the twelve week semester, I got boxes of material. I was astounded as were the students. The materials included in the portfolios ranged from photographs to tapes and videos. They included student-made games, collection of children's jokes, drawings, assignments from other courses, lesson plans, journals/diaries, sculptures, tests and observations. I realized much too late, that in wanting to leave the students room to explore and share in ways meaningful to them, I had forgotten what my own life was like at the end of the term (this was only one of three courses I was teaching).

At their very best, the portfolios were succinct, full of good examples/ demonstrations. Students shared, not only their understanding of children and how they worked with children, but allowed me to get to know something about the children they discussed. At their worst, the portfolios were a mishmash of 
everything done in every class, totally teacher-focused, with nothing about children included. Such students gave the impression that they were centre stage with no audience to consider.

Afterwards (after I had submitted the grades for the course), several students came to me and said that it had been a wonderful experience. One in particular, spoke of it as the most wonderful experience s/he had while in the program. It was interesting that these students were not necessarily those who had done the best job or received the best marks. They shared with me a sense of resourcefulness and self-validation unusual in my experience with students and other forms of evaluation. I was intrigued at how generalized that was but heartened that even a few of my students involved themselves in the invitation to dialogue.

Sonya: I organized the themes according to the four areas highlighted in the guide: their most important learning experiences, personal reactions to the portfolio, results of their peer assessment, and goals and implications for their professional practice. While the responses to these areas were presented as discreet, in reality, there was much overlap.

Students reported a number of different learning experiences as their most important, some from the course and others from their field placements. These experiences included learning the significance of celebrating students' successes and strengths, that being fair does not always mean treating everyone equally, and that both process and product should be assessed in teaching and learning. The students said they learned how to modify and adapt assessment strategies, learned about themselves and why they wanted to teach, and learned that they needed to inquire and reflect more on assessment.

Personal reactions to the portfolio were varied. The students indicated that the portfolio allowed them to enhance their reflective skills as well as explore their thoughts on assessment and how these thoughts changed over the course of the semester. They viewed the portfolio activities as an opportunity to put theory into practice and to develop an assessment philosophy. They thought that the portfolio demonstrated their shift in thinking from that of a student to that of a teacher. It allowed them to 'experience' portfolios. The peer assessment was a valuable component for some. Students were required to share 3-5 responses with a peer and to respond to the peer's feedback. Most agreed that their peers provided them with 'insight' and promoted more reflection because of the questions they asked.

The goals and implications for professional practice that the students discussed, typically, focused on improving their assessment skills. The students were motivated to try more, or particular assessment techniques during their internship. They wanted to try to meet the learning needs of all students. They realized that their previous notions of assessment were based on personal experiences which were not positive. Despite feeling 'reflected out', they also realized the need for a professional to always reflect on personal practice.

Together: The assignment/portfolio was as an invitation. Some students took advantage of the invitation and acted on it. Others missed the point. For such students, neither the structure nor approach used in the exercise mattered. They 
simply did not engage the process. The problem we were left with was how to engage them in appropriate exploration.

As for those students who were very involved, there were those whose portfolios had breadth, offered a wide range of responses, although their responses were largely superficial. Other portfolios had depth but the focus was so precise that the students failed to make the necessary links. We were both looking for breadth and depth.

\section{Assessing Ourselves as Teachers}

donna: I came away from the project wondering about the students that had been in my class; I had a better sense of each as individuals, about their lives and aspirations and understood a bit more of their apprehensions. I also got a sense of how we go about revealing ourselves and come to learn about ourselves and others. I was intrigued by some and, admittedly saddened by others. My sadness came from recognizing that somehow over the semester, I had failed to get to know these students- know and help them recognize how they might in turn, support their future students. It is easy to forget how critical support and encouragement are in learning. While I was exhausted from reading and viewing/reviewing the portfolios, I began to see how I could change not just this assignment but also some of my teaching strategies in order to reach a few more of my students.

Sonya: The students in my class seemed to embrace the constructivist view of learning but found it difficult to put into practice. I struggled with how much structure and instructions to provide them, beyond that included in the handouts. Although I wanted to leave room for them to be creative and work within their learning preferences and needs, students continued to ask questions about what $I$ wanted in the assignment.

Although, at the beginning of the course I heard a lot about my students' unsatisfactory experiences with assessment- from their perspectives as students, I was very encouraged to read their questions and comments coming from the perspective of beginning teachers, when I read their guides. Teachers' approaches to teaching (including assessment) are based on their beliefs about learning and teaching. The portfolio assignment assisted them in making their beliefs explicit. Indeed, it is only when their beliefs are explicit that teachers can reflect on them critically and therefore able to consider how they can influence or change their practice. Seeing the evidence of such reflection among my students reinforced my decision to continue to use this form of evaluation in my course.

Together: Our analysis indicate that portfolios provide preservice teachers with the opportunity to personally reflect on their values, beliefs, and biases with respect to teaching, learning, and child development. As well, portfolios allowed the students to make connections between the objectives of the course and their own learning. 


\section{Teacher/Faculty Portfolios}

We agree with Liebars (1999:164) that "the teacher educator not only models behaviour for preservice teachers but also assesses their learning and understanding”. As instructors, our portfolios had a dual purpose: one was to complete the same assignment as our students and the other was to reflect on our teaching as influenced by this method of evaluation. While this purpose may seem to have two discrete parts, the 'product' and the 'process' were not.

\section{The Approach}

We took on the context and the task provided for our students. Our only evaluation was peer assessment.

donna: My intention in doing the portfolio was to strengthen my understanding of youths. My learning about portfolios was secondary. In total, I completed three activities. In selecting these activities for my portfolio, I wanted to do some things that I was already doing and at least one thing that I had wanted to do, but had not done previously. I decided to informally interview several young men, ranging from ages 13 to 16, about their school experiences as well as the advice they would give to teachers about how best to work with them. Within the semester, I was able to meet with five young men, some of them more than once. I found it most intriguing and instructive that their primary advise to teachers was to "like us," and to "treat us with respect". A second activity that I took on was to read the Newberry Medal books written for young adults. I managed to read about 15 of these in the course of the semester. I found the images of young people in the books to be quite disturbing; almost always in the midst of loss, almost always solving problems on their own. It all seemed so lonely. I went walking with an 11 year old young woman twice a week for the semester, engaging in conversations about what was happening in her life. I walked with this young woman for nine weeks in total and after that we started having tea once a week, and we continue to do so. These three activities were my effort to extend my experiences with, and about young people.

Sonya: I responded to the same mini-case studies and reflective prompts provided to my students. I did not complete the activities they were required to complete in the field because I did not think they were appropriate for my teaching situation. I also completed a guide which highlighted my most important learning experiences, personal reactions to the portfolio, results of my peer assessment, and goals and implications for my professional practice.

\section{Teacher Self/Peer Assessment}

donna: By taking the time to familiarize myself with particular young people, I found a new sense of the tensions that exist for adolescents with regards to how they are seen, what adults actually hear, their desire to be independent while simultaneously wanting to be sheltered from the consequences of that independence. While furthering my understanding of young people was my 
primary goal, the act of constructing a portfolio raised questions about how to select what would be included. As with many of my students, it was easy to get caught up in the making of the portfolio and miss the primary focus. I had lots of clever ideas but then, this was not about clever ideas, it was about experience. I now understand why my students often mistake appearance for substance when constructing portfolios.

Sonya: When I read over my responses to write my guide, I was reminded of one particular issue I often struggle with: how explicit I should be in what I am modeling; that is, the extent to which I should 'make connections' for my students. I believe that students' learning experiences are more meaningful when they make connections themselves. But, how much do I encourage these connections? Is it a 'link' if I make it for them? This issue remains one of my 'works in progress' as I continue to think about it.

My reflections on assessment were not confined to the portfolio and, I suspect, neither were my students'. I informally conferenced with colleagues, both within and outside of the educational psychology area, about what I was doing in my course and what they themselves were doing. These conversations, like my portfolio responses, helped me organize my thoughts on the subject.

I particularly enjoyed this project with donna. While our approach to, and content domains for the portfolio assignments were different, I was somewhat surprised at the similarity of the students' processes and outcomes. It also emphasized how no one activity (or method of assessment) meets the needs of all students despite the flexibility or the structure.

Together: In constructing portfolios at the same time as our students did, our understanding of portfolios changed as well as our understanding of our own and our students' experiences in this process. When we talked about the process, it became clear that our students were not the only ones for whom time was a challenge. It was easy to say that we would do this, it was another thing to actually carry it out.

\section{Metacognitive Threads}

Metacognition, as we use it in this paper, refers to thinking about thinking. The three essential skills of metacognition that allow people to regulate thinking and learning are: planning ('how will I do this?'), monitoring ('how am I doing?'), and evaluation (judgements about the processes and outcomes) (Woolfolk, 1998). Most students come to university as 'natural' learners, not thinking about the learning process because they 'just do it' and do it well (Fleet, Goodchild, and Zajchowski, 1990). So, as Meyer and Tusin (1999) suggest:

teacher educators must help preservice teachers make explicit links among their course work, field experiences, and their pedagogical beliefs to build effective understanding and use of portfolios. Some students seem well prepared to make these connections themselves, whereas others need guidance (p. 136).

Our observations were consistent with that of Meyer and Tusin. 
donna: This assignment was, for my students, particularly disquieting. They found its lack of structure a challenge, especially at the outset. Two weeks after the assignments were given, I began a class by asking them what they were thinking of as activities for their portfolios. We went round the class; there were twenty-seven people and twenty-seven appropriate ideas. From time to time, some chose to check with me in order to find out whether their ideas were fine. Most of the ideas were good. When we talked in class I would often prompt students by asking "have you thought of adding that to your portfolio?" In this way, there was some guidance but by and large, students needed to initiate and give form to their own search for a greater understanding of elementary students.

At the end of the semester, the portfolios were as varied as my students. Some drew on their strengths or interests in drawing, reading, ringette and photography. One student took a young boy bike riding once a week for the semester, another volunteered time in a classroom on a reserve. Keeping their end goal in mind, each student had to plan and monitor a portfolio that demonstrated their efforts to expand their understanding of students. I appreciated the authenticity and vulnerability present in doing an assignment that did not have the same shape or contents as others. For some students, the degree of self-direction made the task overwhelming. There was a need to cut back on the goals they had set themselves. For others, there was a need for more self-reflection. Still for others, there was a sense of satisfaction. As one student put it:

I didn't think that I could do this. When I look at what I have done and what I have learned, I'm amazed. I am so glad now you didn't tell me what to do. That would have limited me. Now I know that I can set my own goals in learning and reach them.

A few students wondered what it was all about even at the end of the course. They were simply involved in performance and presentation; the notion of trying as teachers to understand those we teach seemed lost on them. They were still very much involved in trying to find themselves as students.

In developing my own portfolio, the tension between wanting to stretch my understandings and the time constraints I found myself under, helped me better understand just how difficult a task 'choosing' is. As with many of my students, my ambitions were greater than my follow through. I also found it quite intimidating to share my own portfolio and what I had done, with a colleague. I was doing this voluntarily with a known colleague. Still, sharing this with Sonya has made me more aware of the difference between performance and polish, and struggling to be open to new ideas and experiences. Perhaps the best personal outcomes were that in doing the same assignment as my students, I came to understand their experiences a little more. In choosing to do the project with a colleague, I found out that I was not alone in struggling with how much support my students needed from me in order to construct and use the portfolio as a tool for learning about themselves, about learning itself, and about children.

Sonya: The portfolio assignment in my course invited students to engage in thinking about their thinking about assessment. In their guides, students reported using one, two, or all three of the essential skills of metacognition: planning, 
monitoring, and evaluation. Some viewed the mini-case studies as preparing them for 'real life', while others wrote about their anticipated difficulties in designing and implementing particular assessment strategies. Several students described how they became aware of the fact that many of their beliefs about assessment were based on their experiences as students and how (with their peers' help) they were able to shift their thinking from that of a student, to that of a teacher. Others explained how their portfolios assisted them in identifying their strengths and weaknesses with regards to assessment.

All students participated in self-assessment because they were required to comment on their most important learning experience(s) and the implications of what they had learned, for their professional practice. Almost all described goals for their future development as teachers which included attending workshops and researching assessment.

The students did not see the portfolio, or their 'assessment philosophy', as a final product. They realized that with more knowledge and more experience in the classroom, their beliefs changed and will likely continue to change. Combining theory and practice is often a challenge for preservice teachers.

\section{Conclusion}

While it is easy to see portfolios as ends in themselves, we should bear in mind that portfolios are intended as demonstration sites for knowledge that matters as Wineburg (1997: 260) reminds us in the following:

We have become so enamoured with the architecture of assessmentthe alluring detail of rubrics, exhibitions and portfolios, so carried away by the mantras of authenticity and public display, that we forget to apply equal attention to the very domains we seek to assess.

This idea deserves more attention than we have been able to give it. It causes us to go back and re-examine our use of portfolios in our post-secondary undergraduate classes in educational psychology. Our paper demonstrates how portfolios can be used as a teaching and evaluation tool in teacher education programs, in addition to how they can be used to examine and refine teaching.

We both feel that the experience of using portfolios at the post-secondary level was worthwhile and, we will use this particular technique again. We will continue because of the positive effect the modeling of portfolio assessment had on our students who were preparing to be teachers themselves. An added bonus for each of us was having another colleague with whom to discuss the use of portfolios in our classes and in our own practice. The sharing and dialogue made implementing such a technique easier.

Finally, as Courts and McInerney (1993: 90) have said, "most important, however, is our belief that educational assessment must contribute to improving the lives and learning processes of students and teachers. Otherwise, why bother?” For us, the challenge is to bother. 


\section{References}

Bagget, D. (1994). Using a project portfolio: Empowerment evaluation for model demonstration project. Paper presented at the Illinois Evaluation Technical Assistance Workshop. Champaign, IL.

Boileau, D. (1993). Scholarship reconsidered: A challenge to use teaching portfolios to document the scholarship of teaching. Journal of the Association for Communication Administration, 3-4, 19-24.

Courts, P. and McInerney, K. (1993). Assessment in Higher Education: Politics, Pedagogy and Portfolio. Westport, CT: Praegar.

Curry, S., and Cruz, J. (2000). Portfolio-based teacher assessment. Thrust for Educational Leadership, 29(3), 34-37.

Dietz, M.. (1999). Portfolios. Journal of Staff Development, 20(3), 45-46.

Fenwick, T. and Parsons, J. (1999). A note on using portfolios to assess learning. Canadian Social Studies, 33(3), 90-92.

Fleet, J., Goodchild, F. and Zajchowski, R. (1990). Learning for Success: Skills and Strategies for Canadian Students. Toronto: Harcourt Brace Jovanovich.

Hootstein, E. (1998). The use of portfolio assessment with preservice teachers in social studies. Southern Social Studies Journal, 24(1), 47-60.

Irwin DeVitis, L. (1996). Teachers' voices: Literacy portfolios in the classroom and beyond. Reading Research and Instruction, 35, 223-236.

Kafai, Y. and Resnick, M. (1996). Introduction. In Y. Kafai and M. Resnick (Eds.), Constructionism in Practice: Designing, Thinking, and Learning in a Digital World . Mahwah NJ: Lawrence Erlbaum.

Kozol, J. (1991). Savage Inequalities: Children in America's Schools. New York: Crown.

Liebars, C. (1999). Journals and portfolios: Alternative assessment for preservice teachers. Teaching Children Mathematics, 6(3), 164-169.

Lyons, N. (1999). How portfolios can shape emerging practice. Educational Leadership, 56(8), 6365.

Meyer, D. and Tusin, L. (1999). Preservice teachers' perceptions of portfolios: Process versus product. Journal of Teacher Education, 50 (2), 131-139.

Morgan, B. (1999). Portfolios in a preservice teacher field-based program: Evolution of a rubric for performance assessment. Education, 119 (3), 416-426.

Rakow, S. (1999). Involving classroom teachers in the assessment of preservice intern portfolios. Action in Teacher Education, 21(1), 108-115.

Rogers, S. and Tucker, B. (1993). Video portfolios: Collaboration in literacy teaching assessment. Paper presented at the Annual Meeting of the College Reading Association. Richmond, VA.

Ross, E. (1996). The role of portfolio evaluation in social studies teacher education. Social Education, 60 (3), 162-166.

Ryan, J. and Kuhs, T. (1993). Assessment of preservice teachers and the use of portfolios. Theory in Practice, 32(2), 75-81.

Scanlan, P.and Heiden, D.(1996). External review of portfolios in preservice teacher education: Studying our own practice. Reading Horizons, 36, 297-316.

Stowell, L. (1993). Casting wide the net: Portfolio assessment in teacher education. Middle School Journal, 25(2), 61-67.

Valeri-Gold, M.(1992). Portfolios: Collaborative authentic assessment opportunities for college developmental courses. Journal of Reading, 35(4), 298-305.

Wineburg, S. (1997). Beyond "breadth and depth": Subject matter knowledge and assessment. Theory into Practice, 36(4), 255-261.

Woolfolk, A. (1998). Educational Psychology ( $8^{\text {th }}$ ed.). Toronto: Allyn and Bacon.

Zelazek, J. (1993). Assessing teaching behaviors through video portfolio in field experiences. Paper presented at the Annual Meeting of the Missouri Unit Association of Teacher Educators. Osage Beach, MO. 
Zollman, A. and Jones, D. (1994). Accommodating assessment and learning: Utilizing portfolios in teacher education with preservice teachers. Paper presented at the Annual Conference of the Research Council on Diagnostic and Prescriptive Mathematics. Fort Worth, TX. 
